\title{
Comunicação
}

\section{Potencial alelopático de plantas de cobertura verde de inverno sobre o crescimento do porta-enxerto VR043-43}

\author{
Jean Carlos Bettoni ${ }^{1}$, João Peterson Pereira Gardin², Nelson Pires Feldberg ${ }^{3}$, Marco Antonio Dalbó ${ }^{2}$
}

\begin{abstract}
RESUMO
Nos últimos anos, tem-se verificado aumento no uso da adubação verde de inverno na cultura da videira. Essa adubação proporciona ao vinhedo melhor controle da erosão e manutenção da fertilidade, aumento da macro e microporosidade do solo pela penetração e decomposição das raízes e aumento do teor de matéria orgânica, além da possibilidade de diminuição do uso de herbicidas. Algumas espécies vêm sendo utilizadas, mesmo sem se conhecerem os efeitos secundários para a videira, e poucos trabalhos têm sido realizados para avaliação desses efeitos. O objetivo deste trabalho foi verificar o efeito alelopático de diferentes espécies de plantas de cobertura verde de inverno sobre o desenvolvimento do porta-enxerto VR 043-43. O delineamento utilizado foi inteiramente casualizado, com 19 tratamentos e quatro repetições. Foram preparados extratos das partes aérea e radicular de nove espécies, utilizadas como cobertura verde de inverno. As estacas enraizadas foram colocadas em vasos com areia e, durante 45 dias, duas vezes por semana, foram regadas com solução aquosa de cada extrato e fertilizante. Após esse período, foi avaliado o comprimento das raízes, o número de raízes por estaca, a matéria fresca do sistema radicular e a matéria fresca das brotações. Os resultados obtidos permitiram concluir que, dentre os extratos das espécies estudadas, o que apresentou maior efeito alelopático foi o extrato da parte aérea da gorga (Spergula arvensis), seguido pelo extrato da parte aérea do dente-de-leão (Taraxacum officinale L.). O centeio (Secale cereale L.) e o nabo forrageiro (Raphanus sativus L.) não apresentaram efeito alelopático.
\end{abstract}

Palavras-chave: viticultura, aleloquímicos, enraizamento.

\begin{abstract}
Allelopathic effects of winter cover crops on the growth of the grapevine rootstock VR043-43

In recent years, the use of green manure in vineyards has increased significantly. Green manure has been shown to be effective in soil fertility maintenance and erosion control, increasing soil macro and microporosity by penetration and decomposition of roots, increasing organic matter levels, besides the possibility of reducing herbicide usage in vineyards. A number of cover crop species have been used without knowing the side effects they can cause to the grapevine and few studies have been conducted to assess these effects. The purpose of this study was to evaluate allelopathic effects of winter green manure species on the development of the grapevine rootstock VR 043-43. The experiment was arranged in a completely randomized design, with 19 treatments and 4 replicates. Extracts from the aerial part and roots of nine species used as winter green manure were evaluated for allelopathic effects. Rooted cuttings
\end{abstract}

Recebido para publicação em 05/07/2010 e aprovado em 17/11/2011

Financiamento EPAGRI - Empresa de Pesquisa Agropecuária e Extensão Rural de Santa Catarina.

${ }^{1}$ Engenheiro-Agrônomo. Cooperativa Agropecuária Videirense, Rua Anita Garibaldi, 251, Bairro Centro, 89500-000, Caçador- SC, Brasil. jcbettoni@gmail.com *Autor correspondente.

2Engenheiro- Agrônomo, Doutor, Departamento Pesquisa, EPAGRI. Rua João Zardo, 1660, Bairro Campo Experimental, 89560-000, Videira-SC, Brasil. joaogardin@epagri.sc.gov.br; dalbo@epagri.sc.gov.br

${ }^{3}$ Engenheiro- Agrônomo, Mestre. Departamento Pesquisa, EPAGRI. Rua João Zardo, 1660, Bairro Campo Experimental, 89560-000, Videira-SC, Brasil. nelsonfeldberg@epagri.sc.gov.br

Rev. Ceres, Viçosa, v. 59, n.1, p. 136-141, jan/fev, 2012 
were planted in pots containing sand and were watered with an aqueous solution of each extract and fertilizer twice a week, for 45 days. After this period, the root length, root number per cutting, the fresh weight of roots and shoots were recorded. The results showed that among the species studied, the highest allelopathic effect was found for the extract of the aerial part of corn spurry (Spergula arvensis L.), followed by the extracts of the aerial part of dandelion (Taraxacum officinale L.). Rye (Secale cereale L.) and radish (Raphanus sativus $\mathrm{L}$.) showed no allelopathic effect.

Key words: viticulture, allelochemicals, rooting

\section{INTRODUÇÃO}

Um dos primeiros trabalhos desenvolvidos para o incentivo, aos produtores rurais, do uso de cobertura verde do solo para parreirais, na região Sul, foi iniciado em Bento Gonçalves, em 1982 (Pancotto et al., 2004). Desde então, tem-se verificado significativo aumento no uso de adubação verde de inverno em vinhedos, ano após ano, realizada no período após a colheita dos cachos até o momento da poda de inverno. Antigamente, as práticas de manejo eram realizadas por meio de lavração e capina manual, modificando a estrutura do solo e, em consequencia, a exposição a fenômenos climáticos, o que favorecia os efeitos erosivos. Nos dias atuais, a realidade é outra, o uso de cobertura verde sobre o solo é um dos principais manejos no vinhedo, contribuindo para a melhoria da estrutura do solo, o controle da erosão, a diminuição do uso de herbicidas, propiciando maior vida útil ao pomar.

Várias espécies podem ser usadas para este fim, podendo-se citar aveia-preta (Avena strigosa L.), ervilhaca (Vicia sativa L.), trevo branco (Trifolium repens L.), trevo vermelho (Trifolium pratense L.), tremoço (Lupinus albus L.), nabo forrageiro (Raphanus sativus L.), gorga (Spergula arvensis L.), azevém (Lollium multiflorum L.) e a própria vegetação espontânea (Fráguas et al., 2002). Vargas \& Roman (2006) frisam o centeio como uma espécie altamente concorrente com as plantas daninhas, por seu crescimento inicial vigoroso e capaz de produzir componentes alelopáticos, podendo afetar a germinação de culturas subsequentes. No entanto, Nunes et al. (2002) enfatizam que baixas concentrações de aleloquímicos podem causar estímulo no desenvolvimento de vegetais. Esses mesmos autores ainda relatam que a liberação pode ocorrer por volatilização de substâncias das plantas em estado vegetativo, isso tanto na parte aérea como no sistema radicular.

O manejo da cobertura propicia melhor controle da erosão e manutenção da fertilidade do solo, por um período mais prolongado em relação às áreas sem proteção (Fráguas et al., 2002). De acordo com Giovannini (1999), a semeadura de gramíneas e leguminosas é útil no manejo de solos, sendo que, após completado seu ciclo vital, há a formação de espessa camada de matéria orgânica morta sobre o solo. A cobertura pode ser acamada com rolofaca, obtendo-se uma camada de palha com espessura suficiente para dispensar o uso de herbicidas (Epagri, 2005). Porém, quando plantadas espécies de cobertura em vinhedos em anos de seca, pode ocorrer competição com a videira, prejudicando-a (Giovannini, 1999). Dalbó \& Becker (1994) observaram competição com a videira, quando foram plantadas a ervilhaca e deixada a vegetação nativa permanente, mesmo em anos muito chuvosos, indicando a possibilidade de que isso ocorra por efeitos alelopáticos.

O termo alelopatia foi primeiramente descrito por Molisch, em 1937, e significa a influência de um indivíduo sobre outro, seja prejudicando ou favorecendo o segundo, e sugere que o efeito seja realizado por biomoléculas denominadas aleloquímicos (Ferreira \& Aquila, 2000). Alguns autores definem a alelopatia, enfatizando a inibição de desenvolvimento provocada por substâncias produzidas por plantas próximas (Piña-Rodrigues \& Lopes, 2001). Segundo Olofsdotter et al. (2008), alelopatia pode ser definida como a influência de uma substância química liberada de uma planta viva, agindo sobre o desenvolvimento e o crescimento de outra planta. Essa ferramenta, quando bem utilizada poderá contribuir para o aumento de produtividade.

O objetivo deste trabalho foi verificar o efeito alelopático de diferentes extratos de espécies de plantas de cobertura verde de inverno, sobre o desenvolvimento de estacas enraizadas do porta-enxerto VR 043-43 (Vitis rotundifolia $\mathrm{x}$ Vitis vinifera).

\section{MATERIAL E MÉTODOS}

O experimento foi realizado na Estação Experimental da Epagri, localizada no município de Videira - SC, com altitude de $750 \mathrm{~m}$ e clima, segundo a classificação de Koppen, $\mathrm{Cfb}$ - Temperado (mesotérmico úmido e verão ameno), com temperatura média entre 16 e $17^{\circ} \mathrm{C}$ e precipitação média anual de 1300 a 1500 mm (Collaço, 2003).

O delineamento experimental foi inteiramente casualizado, composto de 19 tratamentos e quatro repetições, com quatro estacas por unidade experimental, totalizando 16 estacas por tratamento. As variáveis analisadas foram: 
número médio de raízes, comprimento médio das três maiores raízes $(\mathrm{cm})$, matéria fresca de raízes $(\mathrm{g})$ e matéria fresca de brotações $(\mathrm{g})$.

As estacas foram do tipo lenhosa, multiplicadas por estaquia, do porta-enxerto VR 043-43, coletadas no matrizeiro da própria Estação Experimental. Após coletadas, as estacas foram embaladas em sacos plásticos e colocadas por 15 dias em câmera de resfriamento, com uma temperatura média de $2{ }^{\circ} \mathrm{C}$. Após esse período, o material foi retirado da câmara fria e selecionaram-se estacas com diâmetro entre 10 e 12 mm e com três gemas. Em seguida, foi feito um corte em bisel no ápice da estaca, 3 $\mathrm{cm}$ acima da gema superior, e um corte transversal, na parte inferior, com aproximadamente $0,5 \mathrm{~cm}$ abaixo da última gema. Na parte inferior da estaca, foram feitas duas lesões, de aproximadamente $3 \mathrm{~cm}$, uma em cada lado, com objetivo de expor o córtex da estaca. Posteriormente, foram imersas por dez segundos em solução de ácido indolbutírico (AIB), com concentração de $3000 \mathrm{mg} \mathrm{L}^{-1} \mathrm{e}$ acondicionadas em leito de areia, em estufa com controle de temperatura (resfriamento) e com irrigação por microaspersão. Quando as estacas apresentaram primórdios radiculares, foram novamente classificadas, descartando-se as mortas e com baixa calogênese, e transplantadas para vasos plásticos preenchidos com areia lavada, sendo quatro estacas por vaso.

Durante sete dias, os vasos permaneceram em aclimatação, passando a ser irrigados, duas vezes por semana, com uma solução composta de água, fertilizante comercial com os nutrientes (nitrogênio $4 \%$, fósforo $4 \%$, potássio $12 \%$, boro $0,03 \%$, cobre $0,05 \%$, manganês $0,04 \%$, molibdênio $0,005 \%$, zinco $0,1 \%$ ) e extrato aquoso das seguintes espécies facilmente encontradas na região: aveia preta (Avena strigosa L.), azevém (Lollium multiflorum L.), ervilhaca (Vicia sativa L.), centeio (Secale cereale L.), gorga (Spergula arvensis L.), trevo branco (Trifolium repens $\mathrm{L}$.), nabo forrageiro (Raphanus sativus $\mathrm{L}$.), aveia louca (Avena fátua L.) e dente-de-leão (Taraxacum officinale L.). Estas últimas, duas plantas espontâneas, são geralmente encontradas em parreirais da região na estação mais fria.

Para a preparação do extrato, foram coletados, separadamente, 500 gramas das partes aérea e radicular de cada espécie citada, triturados por cinco minutos em liquidificador industrial, com $2000 \mathrm{~mL}$ de água destilada. Logo após, o extrato foi peneirado e a parte líquida acondicionada em recipientes de $55 \mathrm{~mL}$, os quais foram congelados. Os extratos foram preparados na semana anterior ao início do experimento.

Para efetuar os tratamentos, os extratos foram descongelados à temperatura ambiente, para posterior preparo da solução. Cada tratamento foi composto de $110 \mathrm{~mL}$ de extrato aquoso, 1,5 mL de fertilizante e $388,5 \mathrm{~mL}$ de água, totalizando $500 \mathrm{~mL}$, exceto a testemunha, que foi composta por 1,5 $\mathrm{mL}$ do fertilizante e 498,5 mL de água. Cada repetição do tratamento foi regada com $125 \mathrm{~mL}$ da solução.

Os dados foram submetidos à análise de variância e as médias dos tratamentos comparadas pelo teste de Tukey, a $5 \%$ de probabilidade, com auxílio do software R. (The R. Development Core Team, 2010).

\section{RESULTADOS E DISCUSSÃO}

O crescimento das estacas de videira foi significativamente influenciado pelos tratamentos com extratos de plantas (Tabela 1). Os extratos da parte aérea da gorga e do dente-de-leão apresentaram maior efeito alelopático para o desenvolvimento da videira. Resultado semelhante foi apresentado por Nunes et al., (2002), que citam a couve (Brassica oleracea var. acephala) como liberadora de aleloquímicos voláteis que inibem o desenvolvimento da videira.

A matéria fresca de raiz (Tabela 1) foi menor nas estacas tratadas com extrato da parte aérea da aveia louca, aveia preta, dente-de-leão, ervilhaca, nabo forrageiro e trevo, quando comparadas com a da testemunha. Da mesma forma, foram menores as massas de matérias frescas de raízes de estacas tratadas com extrato da raiz de aveia louca, aveia preta, azevém, dente-de-leão, ervilhaca e trevo branco. Destaque deve ser dado aos tratamentos com extrato de parte aérea de gorga e dente-de-leão e raiz de dente-de-leão. Os resultados dos demais tratamentos não diferiram dos da testemunha.

Ainda, para esta variável, as espécies de plantas aveia preta, azevém e gorga apresentaram diferenças, quando comparados os extratos da parte aérea com os da raiz (Tabela 1). Estes resultados indicam que substâncias aleloquímicas são produzidas em locais distintos das plantas. Resultados semelhantes foram encontrados por Nunes et al. (2002), quando relatam que a produção de aleloquímicos pode ocorrer em qualquer parte da planta, podendo variar a natureza química dos compostos produzidos nos vários órgãos de um mesmo indivíduo.

A matéria fresca de brotação (Tabela 1) foi afetada pelo extrato de gorga de maneiras distintas, tendo o extrato de parte aérea proporcionado diminuição, enquanto o extrato de raiz proporcionou seu aumento, em comparação com a da testemunha. Esses extratos diferiram também entre si. Os resultados dos demais tratamentos não diferiram dos da testemunha e também não, entre partes aérea e raiz, dentro da espécie. Moraes (2009) relata que a cultura do azevém propiciou melhor controle de plantas daninhas na cultura do milho. Ferreira \& Aquila, (2000), citados por Rossi et al. (2007), observaram a aveia preta e a colza controlarem quase todas as ervas, em função da 
liberação de aleloquímicos sobre as plantas espontâneas, apresentando ação alelopática.

Para o comprimento médio de raízes, verificou-se influência de vários tratamentos. Ocorreu diminuição do comprimento nos tratamentos com extratos de parte aérea de aveia preta, azevém, centeio, dente-de-leão, ervilhaca e gorga; o mesmo ocorreu com extratos do sistema radicular de aveia preta, azevém, dente-de-leão e ervilhaca, quando comparados com os da testemunha. Dentro da espécie, o comprimento médio de raízes diferiu entre os tratamentos com os extratos das partes aérea e a raiz da gorga, novamente evidenciando-se a produção de aleloquímicos em órgãos distintos da planta. Os demais tratamentos não apresentaram diferença.

Os extratos de parte aérea de gorga e de dente-de-leão provocaram a diminuição do número de raízes do portaenxerto VR 043-43 (Tabela 1). Os demais tratamentos não apresentaram influência nesta variável analisada, embora o extrato de raiz de gorga tenha apresentado tendência a aumentar o número de raízes. Dentro da espécie, novamente a gorga apresentou resultados diferentes entre a parte aérea e a raiz e os demais tratamentos não diferiram.

Segundo Nascimento Junior et al. (2007), o centeio produz componentes alelopáticos, os quais são exsudados pelas raízes, interferindo na germinação e desenvolvimento de plantas daninhas e de outras culturas. Neste traba- lho, a ação alelopática do centeio não foi expressa para o porta-enxerto de videira estudado. Conforme Nunes et al. (2002), uma espécie com propriedades alelopáticas influencia somente determinadas espécies.

Quando completam o ciclo, as coberturas verdes formam uma camada de palha sobre o solo, protegendo-o contra efeitos climáticos adversos, além de controle de plantas daninhas. Souza et al. (2010) relatam que a formação de palhada sobre o solo pode afetar as condições de germinação e quebra de dormência de sementes de plantas daninhas, além de prejudicar o desenvolvimento de plântulas; tais situações são observadas graças à barreira física causada pela palhada. Adegas (1997) enfatiza que a cobertura morta serve de isolante, reduzindo a amplitude térmica e hídrica do solo. Segundo Manera (1986), Sousa (1996), Sousa et al. (1996) e Wutke (2001), outra vantagem no uso de cobertura verde é a reposição e manutenção da matéria orgânica, efeito, esse, positivo para a videira. Por outro lado, a desvantagem apresentada para o uso de cobertura morta é o afloramento do sistema radicular que, segundo Pires \& Martins (2003), não é um argumento satisfatório diante de todas as vantagens que proporciona. Esses autores enfatizam que a videira, em solos permanentemente limpos, apresenta melhor resultado no seu desenvolvimento. Segundo Dalbó \& Becker (1994), a videira é uma cultura sensível à competição por outras espécies, durante seu

Tabela 1. Massa fresca de raiz, massa fresca de brotação, comprimento e número médio de raízes por estaca do porta-enxerto de videira VR 043-43 (Vitis rotundifolia X Vitis vinifera), em função dos diferentes tratamentos

\begin{tabular}{|c|c|c|c|c|}
\hline Tratamentos & $\begin{array}{c}\text { Massa fresca } \\
\text { de raiz (g) }\end{array}$ & $\begin{array}{c}\text { Massa fresca } \\
\text { de brotação (g) }\end{array}$ & $\begin{array}{l}\text { Comprimento } \\
\text { de raiz }(\mathrm{cm})\end{array}$ & $\begin{array}{c}\text { Número médio } \\
\text { de raízes }\end{array}$ \\
\hline Testemunha & 30,97 & 13,02 & 13,54 & 14,56 \\
\hline Aveia louca parte aérea & 19,28 & 12,82 & 10,75 & 10,19 \\
\hline Aveia louca raiz & 19,81 & 12,41 & 10,60 & 12,25 \\
\hline Aveia preta parte aérea & 28,96 & 15,45 & 10,21 & 14,56 \\
\hline Aveia preta raiz & 16,91 & 10,83 & 8,31 & 9,44 \\
\hline Azevém parte aérea & 24,70 & 16,47 & 9,09 & 12,04 \\
\hline Azevém raiz & 14,40 & 14,90 & 7,33 & 10,12 \\
\hline Centeio parte aérea & 23,03 & 13,08 & 10,20 & 14,34 \\
\hline Centeio raiz & 24,90 & 15,12 & 12,48 & 15,56 \\
\hline Dente-de-leão parte aérea & 11,23 & 8,64 & 8,41 & 7,62 \\
\hline Dente-de-leão raiz & 17,60 & 9,49 & 8,56 & 8,83 \\
\hline Ervilhaca parte aérea & 18,91 & 11,82 & 8,88 & 12,81 \\
\hline Ervilhaca raiz & 17,16 & 12,45 & 9,14 & 12,29 \\
\hline Gorga parte aérea & 4,49 & 5,76 & 7,84 & 6,86 \\
\hline Gorga raiz & 28,58 & 19,15 & 14,01 & 18,56 \\
\hline Nabo forrageiro parte aérea & 20,30 & 10,55 & 10,96 & 12,44 \\
\hline Nabo forrageiro raiz & 22,42 & 15,13 & 12,23 & 14,83 \\
\hline Trevo branco parte aérea & 16,80 & 10,20 & 12,15 & 13,87 \\
\hline Trevo branco raiz & 19,36 & 12,57 & 13,36 & 14,12 \\
\hline $\mathrm{CV}$ & 19,15 & 16,77 & 12,15 & 17,83 \\
\hline DMS & 9,98 & 5,52 & 3,30 & 5,75 \\
\hline
\end{tabular}

As médias dos tratamentos diferem entre si quando a diferença entre elas for maior que a DMS (diferença mínima significativa) pelo teste de Tukey a $5 \%$ de probabilidade. 
ciclo de crescimento vegetativo. O viticultor deve utilizar espécies de ciclo curto para adubação verde, caso não queira manejar as plantas de cobertura, ou antecipar o plantio para que as plantas completem o ciclo mais precocemente, pois a cobertura dificulta os tratos culturais como poda e amarração, por causa da umidade ocasionada pela chuva e ou pelo orvalho e da dificuldade de deslocamento no parreiral. Algumas espécies, mesmo com a antecipação no plantio, não alteram muito seu ciclo por necessidade de clima ameno para seu crescimento.

Este trabalho foi desenvolvido em condições de casa de vegetação, o que torna importante a realização de ensaios em condições de campo, para verificar e validar este efeito alelopático das plantas de cobertura sobre o crescimento da videira. Segundo Moraes (2009), a parte aérea das plantas de cobertura é a principal fonte de aleloquímicos. Segundo Goldfarb et al. (2009), ocorre maior influência das substâncias alelopáticas nos solos arenosos, em comparação com os solos ricos em matéria orgânica.

Ao se considerar a espécie como um todo (Tabela 2), a parte aérea juntamente com o sistema radicular, o que acontece normalmente com as plantas de cobertura manejadas no campo, verificou-se que as espécies aveia louca, dente-de-leão, ervilhaca, gorga e trevo proporcionam diminuição da massa fresca de raiz do porta-enxerto VR 043-
43. Os demais tratamentos não apresentam efeito significativo. A massa fresca de brotação não é influenciada pelos tratamentos. O comprimento de raizé diminuído com os extratos de aveia preta, azevém, dente-de-leão e ervilhaca, os demais tratamentos não apresentam efeito significativo. $\mathrm{O}$ número de raízes diminuiu somente no tratamento com extrato de dente-de-leão.

Os efeitos alelopáticos foram mais pronunciados sobre a matéria fresca e o comprimento de raiz, do que sobre a matéria fresca de brotação e número de raízes. Observando-se a Tabela 3, verifica-se correlação positiva, significativa, entre essas variáveis, comprovando a associação entre elas. Há muitas evidências da interdependência entre as atividades da raiz e da parte aérea; por exemplo, excelentes correlações entre a taxa de crescimento da parte aérea e a taxa de absorção de nitrogênio, fósforo e potássio (Benincasa \& Leite, 2004). Taxas de respiração de raízes também têm sido altamente correlacionadas com taxas de fotossíntese (próximo ao meio-dia); ainda, taxas de respiração de raízes têm sido correlacionadas com taxas de translocação de açúcares da parte aérea para as raízes (Benincasa \& Leite, 2004). As correlações não são provas de causa e efeito, mas, em uma planta em crescimento, a interdependência entre raízes e parte aérea é um consenso.

Tabela 2. Massa fresca de raiz, massa fresca de brotação, comprimento e número médio de raízes por estaca do porta-enxerto de videira VR 043-43, em função das diferentes espécies

\begin{tabular}{lcccc}
\hline Espécies & $\begin{array}{c}\text { Massa fresca } \\
\text { de raiz }(\mathbf{g})\end{array}$ & $\begin{array}{c}\text { Massa fresca } \\
\text { de brotação }(\mathbf{g})\end{array}$ & $\begin{array}{c}\text { Comprimento } \\
\text { de raiz }(\mathbf{c m})\end{array}$ & $\begin{array}{c}\text { Número médio } \\
\text { de raízes }\end{array}$ \\
\hline Testemunha & 30,97 & 13,02 & 13,54 & 14,56 \\
Aveia louca & 19,54 & 12,62 & 10,67 & 11,22 \\
Aveia preta & 22,93 & 13,14 & 9,26 & 12,00 \\
Azevém & 19,55 & 15,69 & 8,21 & 11,08 \\
Centeio & 23,97 & 14,10 & 11,34 & 14,95 \\
Dente-de-leão & 14,42 & 9,07 & 8,49 & 12,55 \\
Ervilhaca & 18,03 & 12,13 & 9,01 & 12,71 \\
Gorga & 16,53 & 12,46 & 10,93 & 13,63 \\
Nabo forrageiro & 21,36 & 12,84 & 11,60 & 14,00 \\
Trevo & 18,08 & 11,39 & 12,75 & 25,11 \\
\hline CV & 31,50 & 26,27 & 16,61 & 5,34 \\
DMS & 10,81 & 5,69 & 2,97 & \\
\hline
\end{tabular}

As médias dos tratamentos diferem entre si quando a diferença entre elas for maior que a DMS (diferença mínima significativa) pelo teste de Tukey a $5 \%$ de probabilidade.

Tabela 3. Correlação entre as variáveis massa fresca de raiz, massa fresca de brotação, comprimento e número médio de raízes do porta-enxerto de videira VR 043-43

\begin{tabular}{lcccc}
\hline Espécies & $\begin{array}{c}\text { Massa fresca } \\
\text { de raiz }(\mathbf{g})\end{array}$ & $\begin{array}{c}\text { Massa fresca } \\
\text { de brotação }(\mathbf{g})\end{array}$ & $\begin{array}{c}\text { Comprimento } \\
\text { de raizes }(\mathbf{c m})\end{array}$ & $\begin{array}{c}\text { Número médio } \\
\text { de raízes }\end{array}$ \\
\hline Massa fresca de raízes $(\mathrm{g})$ & 1 & & & \\
Massa fresca de brotação $(\mathrm{g})$ & 0,7730 & 1 & 1 & 1 \\
Comprimento de raízes $(\mathrm{cm})$ & 0,5976 & 0,4039 & 0,6787 & 1 \\
Número de raízes & 0,7015 & 0,6240 & & \\
\hline
\end{tabular}

Todos os valores dessas correlações são significativos a $1 \%$ de probabilidade, $\mathrm{N}=76$.

Rev. Ceres, Viçosa, v. 59, n.1, p. 136-141, jan/fev, 2012 


\section{CONCLUSÕES}

O extrato de raiz de gorga proporciona aumento na matéria fresca de brotação. Os extratos da parte aérea de aveia louca, aveia preta, dente-de-leão, ervilhaca, nabo forrageiro e trevo e os extratos de raiz de aveia louca, aveia preta, azevém, dente-de-leão, ervilhaca e trevo branco diminuem a matéria fresca de raiz do porta-enxerto VR 043-43 nas condições do experimento.

O extrato de parte aérea de gorga diminui a matéria fresca de raiz, a matéria fresca de brotação, o comprimento de raiz e o número de raízes.

O extrato de dente-de-leão apresenta os maiores efeitos alelopáticos negativos ao desenvolvimento do portaenxerto VR 043-43.

\section{AGRADECIMENTOS}

À EPAGRI, Empresa de Pesquisa Agropecuária e Extensão Rural de Santa Catarina, Estação Experimental de Videira-SC, pelo suporte técnico.

\section{REFERÊNCIAS}

Adegas AS (1997) Manejo integrado de plantas daninhas. Pato Branco, Passo Fundo: Aldeia Norte. Anais..., (Conferência Anual de plantio direto). 2:17-26.

Benincasa MMP \& Leite IC (2004) Fisiologia Vegetal, Jaboticabal: Funep, 169p.

Collaço M (2003) Secretaria de Estado de Desenvolvimento Regional - SDR: Videira Caracterização Regional. 34p.

Dalbó MA \& Becker M (1994) Avaliação de Sistemas de Manejo do Solo para a Cultura da Videira. Pesquisa Agropecuária Brasileira, 29:236-266.

Epagri (2005) Normas técnicas para o cultivo da videira em Santa Catarina. Florianópolis, Sistemas de Produção 33, 67 p.

Ferreira AG \& Aquila MEA (2000) Alelopatia: uma área emergente da ecofisiologia. Revista Brasileira de Fisiologia Vegetal, 12:175-204.

Fráguas JC, Alvarenga AA, Abrahão E, Regina AMA (2002) Calagem e Adubação para Videiras e Frutíferas de Clima Temperado. Belo Horizonte: EPAMIG, (Boletim Técnico nº 65).

Giovannini E (1999) Produção de Uvas para Vinho, Suco e Mesa. Porto Alegre: Renascença, 364p.

Goldfarb M, Pimentel LW, Pimentel NW (2009) Alelopatia: relações nos agroecossistemas. Tecnologia \& Ciência Agropecuária, 3:23-28.

Moraes PVD (2009) Alelopatia de espécies de cobertura na inibição de plantas daninhas na cultura do milho. Brasília, Revista Brasileira de Agroecologia, 4:117.

Nascimento Junior A, Teixeira MCC, Bianchin V, Lazzari R, Tonello M \& Moura R (2007) O uso de centeio como cultura intercalar em videiras. Ministério da Agricultura, Pecuária e Abastecimento. Disponível em: < http://www.cnpt.embrapa.br/biblio/co/ p_co206.htm>. Acessado em: 1 de dezembro de 2009.

Nunes MUC, Carvalho LM, Netto JBAA (2002) Alelopatia: Ferramenta importante no manejo de sistemas agrícolas de produção. Ministério da Agricultura, Pecuária e Abastecimento. Aracaju, Circular Técnica, n.28.
Olofsdotter M, Navarez D, Moody K (2008) Allelopathic potential in rice (Oryza sativa L.) germplasm. Annals of Applied Biology, 127:543-560.

Pancotto AII, Capoani PRB, Salvador GL (2004) Cobertura verde do solo em viticultura. Extensão Rural e Desenvolvimento Rural Sustentável, 1:12 p.

Pires EJP, Martins FP (2003) Técnicas de cultivo. In: Celso Valdevino Pommer (edit.). Uva: Tecnologia de produção, póscolheita, mercado. Porto Alegre: Cinco Continentes, p. 351403.

R Development Core Team (2010). R: A language and environment for statistical computing. R Foundation for Statistical Computing, Vienna, Austria. Disponível em: < http:/ /www.R-project.org>. Acessado em: 22 de novembro de 2009.

Piña-Rodrigues FCM \& Lopes BM (2001) Potencial Alelopático de Mimosa caesalpinaefolia Benth sobre sementes de Tabebuia Alba (Cham.) Sandw. Floresta e Ambiente, 8:130-136.

Rossi A, Rufato L, Giacobbo CL, Costa VB, Vitti MR, Mendez ME \& Fachinello JC (2007) Diferentes manejos para cobertura vegetal de aveia preta em pomar no Sul do Brasil. Bragantia, 66:457-463.

Souza AP, Lima ME, Carvalho DF, Guerra JGM, Andrade IPS \& Rocha HS (2010) Influência da decomposição de diferentes resíduos vegetais submetidos a lâmina de irrigação no comportamento da vegetação espontânea. Acta Scientiarum- Agronomy, $32: 317-324$.

Vargas L \& Roman ES (2006) Cultivo de centeio: Manejo e controle de plantas daninhas. Passo Fundo, Embrapa Trigo, Sistema de produção, 1-2a edição.

Wutke E B (2001) Resultados de pesquisas com adubação verde intercalar na videira Niagara. Jaboticabal, Dia de Campo. Mimeo. 